\title{
Functional Impact Analysis for Complex Critical Infrastructure Systems
}

\author{
Dustin Witte \\ Institute for Security Systems, University of Wuppertal, Germany. E-mail: witte@uni-wuppertal.de \\ Sylvia Bach \\ Department of Public Safety and Emergency Management, University of Wuppertal, Germany. \\ E-mail: sbach@uni-wuppertal.de \\ Daniel Lichte \\ Institute for the Protection of Terrestrial Infrastructures, German Aerospace Center (DLR), Germany. \\ E-mail:daniel.lichte@dlr.de
}

Frank Fiedrich

Department of Public Safety and Emergency Management, University of Wuppertal, Germany.

\author{
Kai-Dietrich Wolf \\ Institute for Security Systems, University of Wuppertal, Germany.
}

\begin{abstract}
The well-being of the population depends to a large extent on services of critical infrastructures (CIs). It is a wellknown fact that the dependencies between CIs lead to even greater impacts on society in the case of malfunctions. To assess these impacts, understand and mitigate them, it is essential to determine and possibly quantify the dependencies. The approach described here consists of three steps. First, the disruptive event for which the impacts should be analyzed is defined (e.g. a blackout). In a second step, the infrastructure system is modeled. For this purpose, the system is divided into its entities according to common CI definition. Then, the possible service levels of each entity are assessed and quantified, such as standard operation mode, emergency operation mode or breakdown. Logically linked requirements for reaching those levels are defined, either autonomously or as an external dependency (e.g. a power generator), forming a system of dependent services. In a third step, impacts of events are analyzed by degrading selected services and calculating the effects on other services according to the logically linked requirements. Uncertainties can be described by specifying probabilities for service levels. The development over time can be examined by evaluating the impacts of sequential time intervals, e.g. for a regional blackout, where more CIs will face difficulties over time.
\end{abstract}

Keywords: Critical Infrastructures, Modeling, Cascading Effects, Boolean Logic, Functional Impact Analysis, Uncertainty, Uncertainty Propagation.

\section{Introduction}

From the perspective of municipality disaster management, being prepared for any disruptive event affecting inhabitants would be the ideal state. As desirable as this is, as costly it would be, at least if the plain return on investment was included in the calculation (Kousky et al., 2019). A more feasible approach is to know as much as possible about the boundary conditions in a community and search for existing leverages. Where does the highest potential for optimization of resilience lie? Where are prevalent vulnerabilities?

The approach shown in this paper includes the knowledge about critical infrastructures and their interdependencies in a model to analyze the impacts of a disruptive event on the functionality of critical infrastructures and to derive an indicator for the well-being of the potentially hit population in a given community. For this purpose, the authors define a well-being indicator, displaying the state of criticality regarding relevant service provision for the population during a disruption.

The model is generic in a way that it can be adapted to the depth of knowledge by in- or excluding actors, indicators that demonstrate service levels of said actors or stochastic probabilities for achieving specific service levels.

By varying input data, effects of resilience enhancing measures on the population can be shown. Another use case could be benchmarking with other municipalities for a realizable set of best 
practices where comparability is given.

\section{Background}

\subsection{Critical infrastructure systems}

The fact that critical infrastructures (CIs) have to be considered rather as a system of critical infrastructures and are-in varying degrees-dependent on each other is well known (Rinaldi et al., 2001; Kröger and Zio, 2011; Hokstad et al., 2012; Setola et al., 2016). The complexity of such a system-ofsystems grows with the number of incorporated critical infrastructures it consists of. The number is usually correlated to the extend of the considered area. Germany, for example is a country of roughly 80 million people, all in need of energy, water, health care, food, private and public transport, internet and other means of communication. Moreover, a functioning federal, state and municipal administration, financial services as well as an adequate access to media and culture are prerequisite for a vital society (BBK, 2003). Models trying to cover all mentioned aspects will either be too complex and therefore incomprehensible or will include too little consistent and evaluated data to be of value.

On a municipality level, the evaluation of data is easier accomplished. Here, the operators of critical infrastructures often already work together or are at least known to each other, e.g. by municipal crisis units or through the work of municipal civil protection structures.

\subsection{Impact analysis}

Different approaches are described in the literature to model interdependencies and analyze the impact of disruptive events on infrastructure systems.

Tien (2014) and Johansen and Tien (2017) describe an Bayesian network based approach for component-based probabilistic modeling and reliability assessment. The approach is demonstrated on a system of interdependent water, power and gas networks. The overall functioning of each network is determined by the functioning of one of several minimum link sets of components of the water, power or gas network. Failure probabilities are determined for each component depending on the intensity of given disruptions. The approach describes the system in detail, but seems to be specialized for the analysis of technical systems.

A more general approach is described by Marti (2014), using an input-output model to find optimal disaster response strategies. The infrastructure system is construed as a system of production units coupled by transportation and allocation units. The approach is illustrated by a system consisting of a power station, a water station, a hospital and residences, each represented by a production unit. Inputs of units are determined by either a direct relation to outputs of other units or additional unit affecting factors. The relationship is specified by input-output tables, which describe the input levels required to achieve a defined output level. Impacts on the residents are aggregated to a well-being index by the corresponding production unit (Tofani et al., 2016). The approach allows a well-beingoptimal allocation of resources under given boundary conditions, but uncertainties regarding the boundary conditions and uncertain time-dependent developments are not covered.

The approach presented in the following adapts the flexible model description in Marti (2014), but aims to investigate different possible timedependent scenarios and to reflect impacts probabilistically.

\section{Approach}

The approach was developed in context of a power outage, but can be applied to various types of disruptions and systems. Nonetheless, the procedure is illustrated by means of a power outage.

The approach is divided into three steps. First, the disruptive event, for which impacts should be investigated, are defined. On this basis, the system, associated boundaries, and the time horizon to be studied are then identified. Secondly, a model of the infrastructure system is set up that represents the services and dependencies relevant in the context of the disruptive event. Finally, the impacts of the disruptive event on the infrastructure system are assessed by setting boundary conditions and resolving the dependencies in the model.

\subsection{Defining the disruptive event and scope of analysis}

The functionality of the interlinked critical infrastructures depends on a stable and safe environment. Disruptive events like extreme weather, seismic activity, a terroristic attack or a malfunction due to human error often have a specific starting point within the greater system-of-systems and affect other CIs through the web of interdependencies.

A power outage affecting a defined area or municipality hits this area more or less equally grave in terms of a drop in service levels: some CIs have an emergency power supply, but households, resident physicians, shops, pharmacies etc. will stop functioning immediately or only minutes or hours after the blackout. They rely on electricity for cashier, reception, access or supply systems, food and water provision, etc.

The initial event underlying the model described in the course of this paper is a power outage due to the failure of two $220 \mathrm{kV}$ transformers in a substation, leading to an automatic shutdown process of a third transformer on the $380 \mathrm{kV}$ level. Depending on the gravity of damage caused by or immediately before this shutdown, the functionality of this third transformer can either be restored after approx. 24 or 72 hours. 
As the blackout duration affects the impact, the time horizon for the analysis is divided into intervals to reflect the time-dependent development. Here, used time intervals are $0 \mathrm{~h}$ to $6 \mathrm{~h}, 6 \mathrm{~h}$ to $24 \mathrm{~h}$ and $24 \mathrm{~h}$ to $72 \mathrm{~h}$ inspired by Petermann et al. (2011).

\subsection{Modeling the infrastructure system}

The model reflects the information available about the infrastructure system and provides the basis for the subsequent assessment of impacts.

Here, a municipality with approx. 350000 inhabitants in Germany and its specific conditions and parameters provides required data for the model. In order to collect data, a workshop has been carried out where all operators of previously defined critical infrastructures were invited. During this workshop, performance indicators representing the services of the organizations were compiled as well as dependencies within and among the represented organizations. In the following, an organization is referred to as an entity.

\subsubsection{Defining infrastructure entities}

To improve comprehensibility and reduce complexity, it is focused on a critical infrastructure. This then serves as the center of the surrounding network of other dependent or those on which the focused critical infrastructure depends. Here, the health care related CI "hospital" was chosen to be in the center of this web, with its interdependencies to the local network operator for electricity, the network operator for water and wastewater and public transport. A list of the entities evaluated in the model municipality is shown in Table 1 .

The regional approach allows for more detailed information about actual networks and dependencies between the entities to be included in and validate the model.

The exemplary system described in the following includes the entities hospital, energy, water/wastewater and transport system.

\subsubsection{Determining entity services}

The main objective of the complex system of CIs is to provide an adequate level of public welfare to the population in terms of economic prosperity as well as vital services (Rinaldi et al., 2001; Min et al., 2007). Therefore, as the measure of interest for the model at hand and its focus on healthcare, the well-being of the population has been chosen. It is expressed as a "traffic light indicator" derived from the service levels of the entities included.

To be included in and of value for the model, the services provided for society by the entities need to be determined and quantified. For each entity, services describing their performance are determined. Services can be internal, e.g. the entity's own emergency power generation, or external,
Table 1. Entities of the model municipality

\begin{tabular}{|c|c|}
\hline CI sector & Entity \\
\hline Energy & $\begin{array}{l}\text { Transmission System Operator (TSO) } \\
\text { Network Operator (NO) }\end{array}$ \\
\hline $\begin{array}{l}\text { Water/ } \\
\text { Wastewater }\end{array}$ & Network Operator (NO) \\
\hline $\begin{array}{l}\text { Healthcare } \\
\text { and Public } \\
\text { Health }\end{array}$ & $\begin{array}{l}\text { Hospital } \\
\text { Resident Physician } \\
\text { Dialysis Clinic } \\
\text { Nursing Home }\end{array}$ \\
\hline $\begin{array}{l}\text { Transport } \\
\text { Systems }\end{array}$ & Public Transport \\
\hline $\begin{array}{l}\text { Emergency } \\
\text { Services }\end{array}$ & $\begin{array}{l}\text { Fire Department } \\
\text { Police } \\
\text { Federal Agency for Technical Relief }\end{array}$ \\
\hline $\begin{array}{l}\text { Government } \\
\text { Facilities }\end{array}$ & $\begin{array}{l}\text { Municipal Crisis Unit } \\
\text { Municipal Information and } \\
\text { Communications Technology }\end{array}$ \\
\hline
\end{tabular}

e.g. the drinking water provided to other entities. Both, quantitative as well as qualitative service descriptions are possible. Qualification is realized by defining levels of service including a priority ranking. Quantification allows for additional calculations, but may not always be feasible.

Generally, determination and quantification is achieved by means of established or specifically defined model-related indicators. Due to the fact that the model at hand is fed with data from the municipality of an existing German city, those indicators were actively extracted from the organizations representing the entities. For this purpose, expert interviews were set up and a joint workshop was carried out, attended by representatives of the entities shown in Table 1. Table 2 is a summary of possible indicators able to define service levels of the entities of the model presented in this paper. It summarizes the set of indicators used in the simplified model. The more indicators used in the model, the more complex it becomes. However, the number of used indicators should always lead to a balance between model complexity and information gain. Assuming a sufficient quality of the indicators, the more significant and informative the results become regarding strengths (resilience) and weaknesses (vulnerabilities) of the system.

The above introduced service levels are included in the model described in this paper to obtain the well-being indicator for the affected population. Potentially achievable states - apart from "normal" are non-critical (green), partially critical (yellow) and critical (red), where the state definitions are valid in a disaster context. The status "normal" 
Table 2. Entities, services and service levels of the simplified infrastructure system

\begin{tabular}{|c|c|c|}
\hline Entity & Service & Service Levels \\
\hline TSO & electric power supply (transmission) & normal, outage \\
\hline NO (Electric Utility) & $\begin{array}{l}\text { electric power supply (distribution) } \\
\text { local power generation } \\
\text { (e.g. waste-to-energy plant) }\end{array}$ & $\begin{array}{l}\text { normal, limited, minimal, failure } \\
\text { level in MW }\end{array}$ \\
\hline NO (Water Utility) & $\begin{array}{l}\text { drinking water supply (distribution) } \\
\text { drinking water storage } \\
\text { emergency power supply } \\
\text { (e.g. pumps for water/wastewater) }\end{array}$ & $\begin{array}{l}\text { normal, emergency, failure } \\
\text { level in } \mathrm{m}^{3} \\
\text { operative, inoperative }\end{array}$ \\
\hline Hospital & $\begin{array}{l}\text { inpatient capacity } \\
\text { outpatient capacity } \\
\text { emergency care capacity } \\
\text { staff availability } \\
\text { drinking water supply } \\
\text { electric power supply } \\
\text { diesel fuel storage }\end{array}$ & $\begin{array}{l}\text { sufficient, insufficient } \\
\text { sufficient, insufficient } \\
\text { sufficient, insufficient } \\
\text { sufficient, insufficient } \\
\text { normal, failure } \\
\text { normal, emergency, failure } \\
\text { level in liters }\end{array}$ \\
\hline Public Transport & $\begin{array}{l}\text { rail-bound traffic (supraregional) } \\
\text { road-bound traffic (regional) } \\
\text { diesel fuel storage }\end{array}$ & $\begin{array}{l}\text { normal, limited, outage } \\
\text { normal, outage } \\
\text { level in liters }\end{array}$ \\
\hline
\end{tabular}

cannot be reached because of the model's boundary condition of a power outage. The well-being indicator for the population derived from the different states of the entities is summarized in Fig. 1.

\subsubsection{Determining service dependencies}

As the CIs are part of an interdependent system, dependencies between the entity services exist. Additionally, their characterization may be timedependent. To analyze the impact of the disruptive event, all potential dependencies between the services need to be identified and described. Here, a potential dependency is described by requirements, i.e. the conditions under which an entity can provide a service at a certain level. They may refer to other services, either of the same entity or other entities, and are logical linked. The dependencies are represented by a directed graph.

This approach is illustrated in Fig. 3. Here, a model of the dependencies of the hospital's internal electric power supply on the electric utility power supply and the hospital's internal diesel fuel storage is shown. For regular operation, the hospital requires normal power supply by the electric utility. To continue to operate under emergency mode, there are two possible options with decreasing priority. Either the hospital is emergency-supplied by the electric utility or a hospital's internal emergency power generator is used. The electric utility can provide this service solely when their own power supply is limited to a certain degree. The

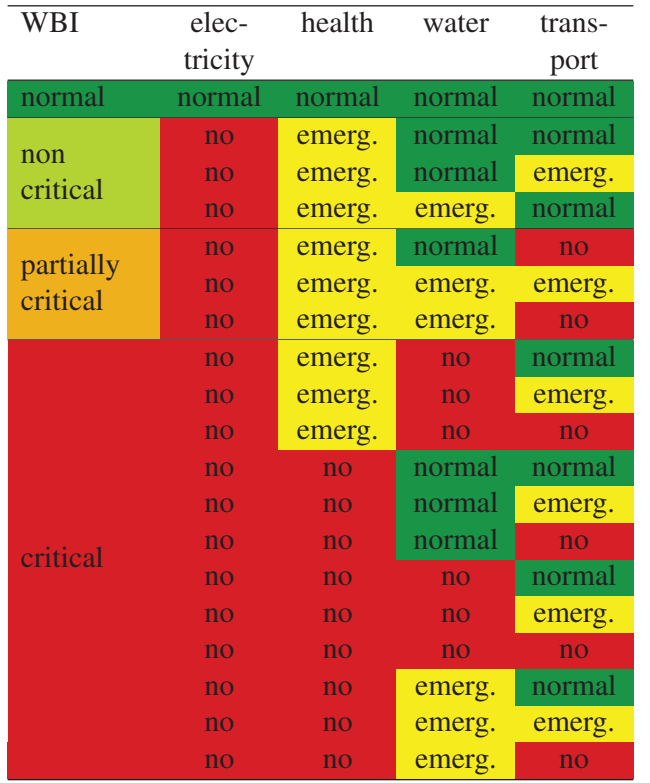

Fig. 1. Feasible states for well-being indicator (WBI) of example

service is not available with minimal or failed power supply of the utility. Here, the use of the internal emergency power generator is modeled 


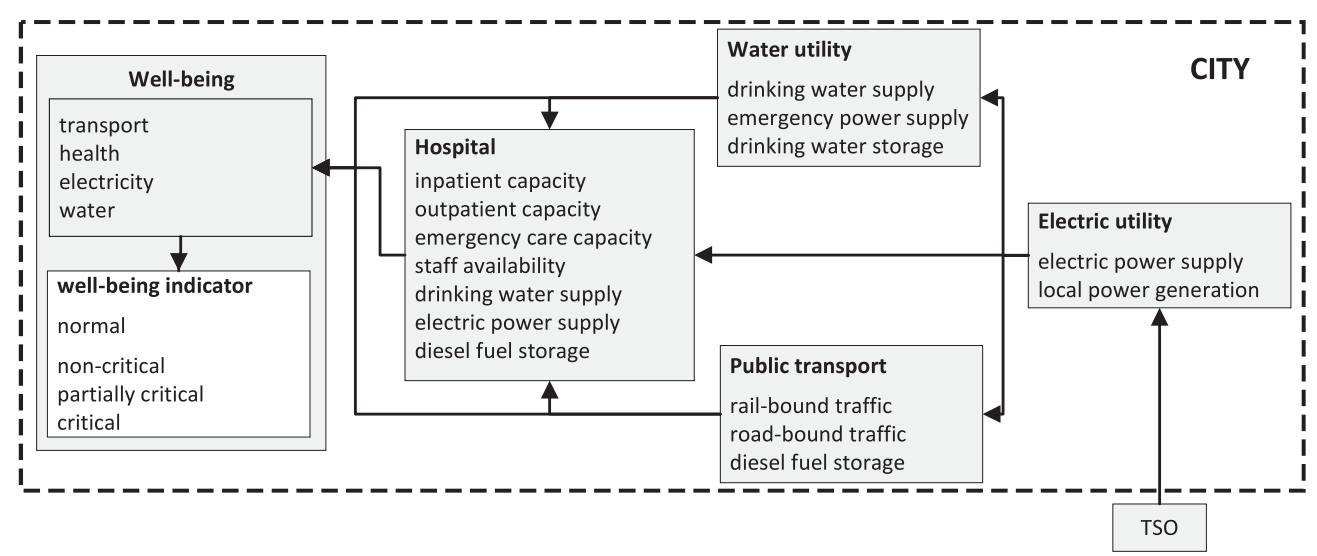

Fig. 2. System boundaries/scope of analysis (dotted line), entities and indicators defined for the model described

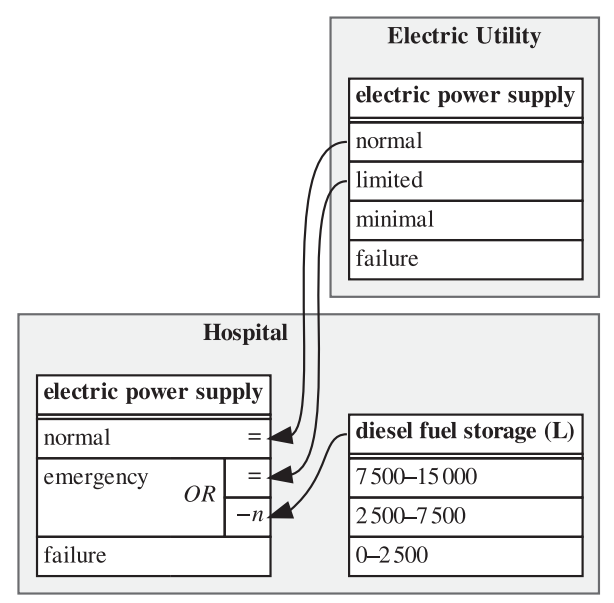

Fig. 3. Dependencies of hospital internal electric power supply

by consuming diesel from the internal diesel fuel storage. The required amount of fuel should be quantified with regard to the investigated time intervals.

As shown in Fig. 3, multiple types of requirements can be formulated. The requirements and logical links used in the simplified model are described in Table 3 and Table 4.

The dependencies were identified in the joint workshop. As the number of the identified entities and the complexity of their dependencies goes beyond the scope of this paper, a simplified view focusing on the identified hospital's dependencies is depicted in Fig. 2.
Table 3. Requirements

\begin{tabular}{ll}
\hline Symbol & Description \\
$=,>, \geq \quad \begin{array}{l}\text { The requirement is fulfilled if the service } \\
\text { an entity depends on provides a specific } \\
(=) \text { or minimal }(>, \geq) \text { service level. }\end{array}$ \\
& $\begin{array}{l}\text { The requirement is fulfilled if the level of } \\
\text { the service depending on can be decreased } \\
\text { by } n \text { without falling below zero. }\end{array}$
\end{tabular}

Table 4. Logical links

\begin{tabular}{ll}
\hline Symbol & Description \\
\hline$A N D$ & $\begin{array}{l}\text { The AND operation is fulfilled if all of } \\
\text { multiple requirements are fulfilled. All } \\
\text { requirements are scanned. }\end{array}$ \\
OR & $\begin{array}{l}\text { The OR operation is fulfilled if one of } \\
\text { multiple requirements is fulfilled. The re- } \\
\text { quirements are scanned in a predetermined } \\
\text { order. The scan stops once a requirement } \\
\text { is fulfilled. }\end{array}$ \\
\hline
\end{tabular}

\subsection{Assessing impacts}

Based on the model description of the infrastructure services and their dependencies shown in Section 3.2, the impact of the disruptive event on the infrastructure system is assessed. The development over time is considered by dividing the time horizon into time intervals and assess these time intervals in sequence. 


\subsubsection{Setting boundary conditions}

Independent services are starting points of the assessment. Their service levels are determined, e.g. the amount of stored diesel fuel or the amount of produced electric energy by the local power plants. Other boundary conditions affecting the service levels, such as the shift change of the hospital staff, are included in the assessment by adding them as additional services.

The boundary conditions may be affected by uncertainties and are therefore described by random variables. With regard to the example, one source of uncertainty relates to the municipal power generation. Despite the disconnection from the transmission network, the electric utility company may have the opportunity to produce and distribute electric energy on a reduced scale, e.g. by a municipal waste-to-energy plant or combined heat and power station. However, the isolated operation of these plants without connection to a transmission network is fragile and the obtainable power level is not guaranteed.

The amount of stored diesel fuel should be considered as another source for uncertainty. As the level of the diesel fuel storage may vary over time, the actual level is uncertain in case of an occuring disruptive event.

The values and probability distributions of the boundary conditions for the simplified example are summarized in Fig. 5.

Table 5. Boundary conditions

\begin{tabular}{|c|c|}
\hline Service & Service Level \\
\hline $\begin{array}{l}\text { TSO } \\
\text { electric power supply }\end{array}$ & 0-72 h: outage \\
\hline $\begin{array}{l}\text { Electric Utility } \\
\text { local power generation }\end{array}$ & 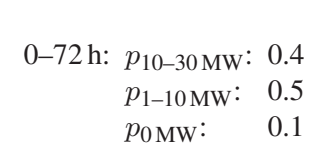 \\
\hline $\begin{array}{l}\text { Water Utility } \\
\text { drinking water storage } \\
\text { emerg. power generation }\end{array}$ & $\begin{array}{l}\text { initial: } 80000 \mathrm{~m}^{3} \\
\text { 0-72h: yes }\end{array}$ \\
\hline $\begin{array}{l}\text { Local Public Transport } \\
\text { diesel fuel storage }\end{array}$ & $\begin{aligned} \text { initial: } \mathcal{N}(600000 \mathrm{~L} \\
\left.100000^{2} \mathrm{~L}^{2}\right)\end{aligned}$ \\
\hline $\begin{array}{l}\text { Hospital } \\
\text { diesel fuel storage } \\
\text { shift change }\end{array}$ & $\begin{array}{l}\text { initial: } 10000 \mathrm{~L} \\
0-24 \mathrm{~h}: \text { no } \\
24-72 \mathrm{~h}: \text { yes }\end{array}$ \\
\hline
\end{tabular}

\subsubsection{Resolving dependencies}

With given boundary conditions, the impacts on the depending services are calculated according to the dependencies, resolving them successively. For each time interval, the dependencies are resolved in sequence, so that each dependent service is resolved after the service it depends on. The order is determined by topological sorting (Sanders et al., 2019), hence the assessment method suggested here is limited to acyclic dependency graphs. However, this limitation is acceptable in the example considered in this paper.

A dependency is resolved if the predefined logically linked requirements of the service levels are fulfilled. The service levels are evaluated sequentially according to their level ranking starting with the highest priority level. The evaluation stops at the service level where the requirements are fulfilled. This is the service level, under which the entity continues service provision.

The procedure is illustrated by the example of the electric power supply of the hospital previously introduced in Fig. 3. First, the requirement for normal power supply is checked. If fulfilled, the procedure ends and the requirements for emergency power supply remain unused. However, if unfulfilled, the "or-linked" requirements for emergency power supply are checked. The power supply fails, if the link is also unfulfilled.

To consider uncertainties of the boundary conditions a Monte Carlo simulation is applied by sampling service levels according to the specified probability distributions. Each combination of sampled boundary conditions represents a possible scenario.

Time intervals are calculated in sequence based on the results of the previous time interval.

\section{Results for the exemplary model}

The assessment of the example described in Section 3 results in scenarios, showing possible impacts of the disruptive event on the services of the infrastructure system in subsequent time intervals under uncertain boundary conditions. The frequency of scenario occurrence and the therein described service levels within the Monte Carlo simulation mark their probability, respectively. Thus, probability distributions describing achievable service levels can be calculated for each infrastructure service for each time interval.

In Fig. 4 the probability distribution of the hospital internal power supply and its dependencies (cf. Fig. 3) are exemplarily visualized for two time intervals. The results show that within the first $6 \mathrm{~h}$ after the disruptive event, it is certain that the hospital is able to operate under emergency power supply. In the time interval from $24 \mathrm{~h}$ to $72 \mathrm{~h}$ after the disruptive event however, availability of the emergency power supply is uncertain. The continuation of emergency power supply is calculated 


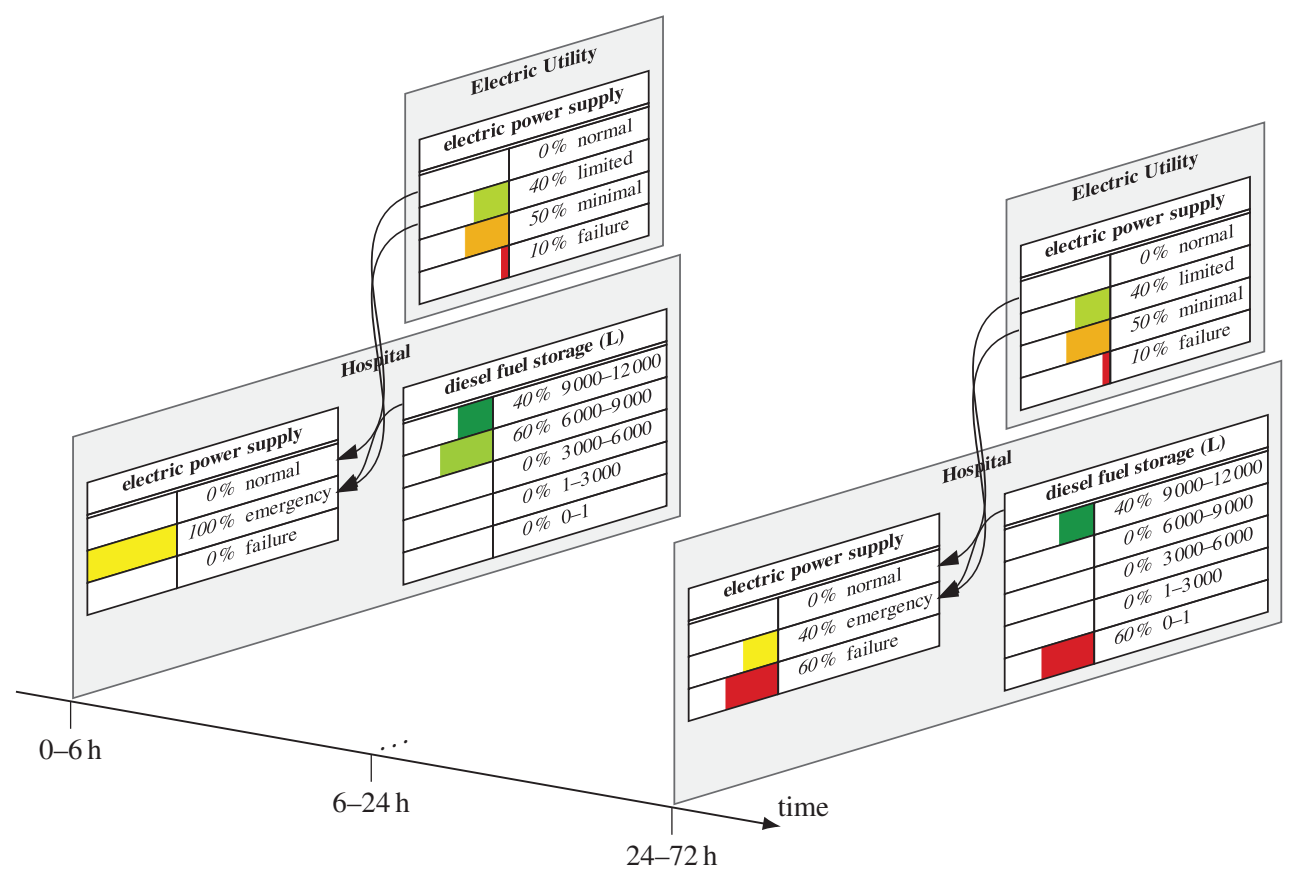

Fig. 4. Assessment result of the hospital internal electric power supply for two time intervals

with a probability of 0.4 and the failure with a complementary probability of 0.6 .

The aggregated impacts on the population are shown in Fig. 5 by means of the well-being indicator. Based on the results, at least two reasonable statements on criticality development can be made. Within the first $6 \mathrm{~h}$, the impacts on the population are non critical while critical impacts can be estimated after $24 \mathrm{~h}$. In contrast, the development between $6 \mathrm{~h}$ and $24 \mathrm{~h}$ is uncertain as non critical impacts and (partially) critical impacts are almost equally probable.

\section{Conclusion}

For the results of the chosen disruptive event and entities, only a selection of services, indicators and parameters were defined and assessed. Still, in the time-dependent development (Fig. 5) the changes in criticality of the condition of the considered services - and as a result the state of the well-being of the population-can be shown. It was possible to implement the consideration of uncertainties in a sensible way increasing usability of the model by yielding different scenarios. The level of detail for the input variables can be adjusted, allowing for varying degrees of accuracy. Thus, the presented model may serve as a suitable and generic tool to display interdependencies of critical infrastructures in a defined area and assess impacts on the wellbeing of the population.
The results reveal time-dependent variances of the well-being indicator that hint to propagation of the uncertainties included in model input. Further investigation of these effects is needed, as they could serve as an evaluation criterion for the severity of criticality development. Additionally, understanding and using the suspected uncertainty propagation in decision making could be a powerful tool to consider lacking input information and model behavior.

\section{References}

BBK, Federal Office for Civil Protection and Disaster Assistance (2003). Definition of critical infrastructures in germany. https://www.bbk. bund.de/DE/AufgabenundAusstattung/

KritischeInfrastrukturen/

kritischeinfrastrukturen_node.html (last viewed 24 March 2021).

Hokstad, P., I. B. Utne, and J. Vatn (Eds.) (2012). Risk and Interdependencies in Critical Infrastructures. A Guideline for Analysis. Springer Series in Reliability Engineering. London: Springer.

Johansen, C. and I. Tien (2017). Probabilistic multiscale modeling of interdependencies between critical infrastructure systems for resilience. Sustainable and Resilient Infrastructures 3(1), 115.

Kousky, C., L. Ritchie, K. Tierney, and B. Lingle 


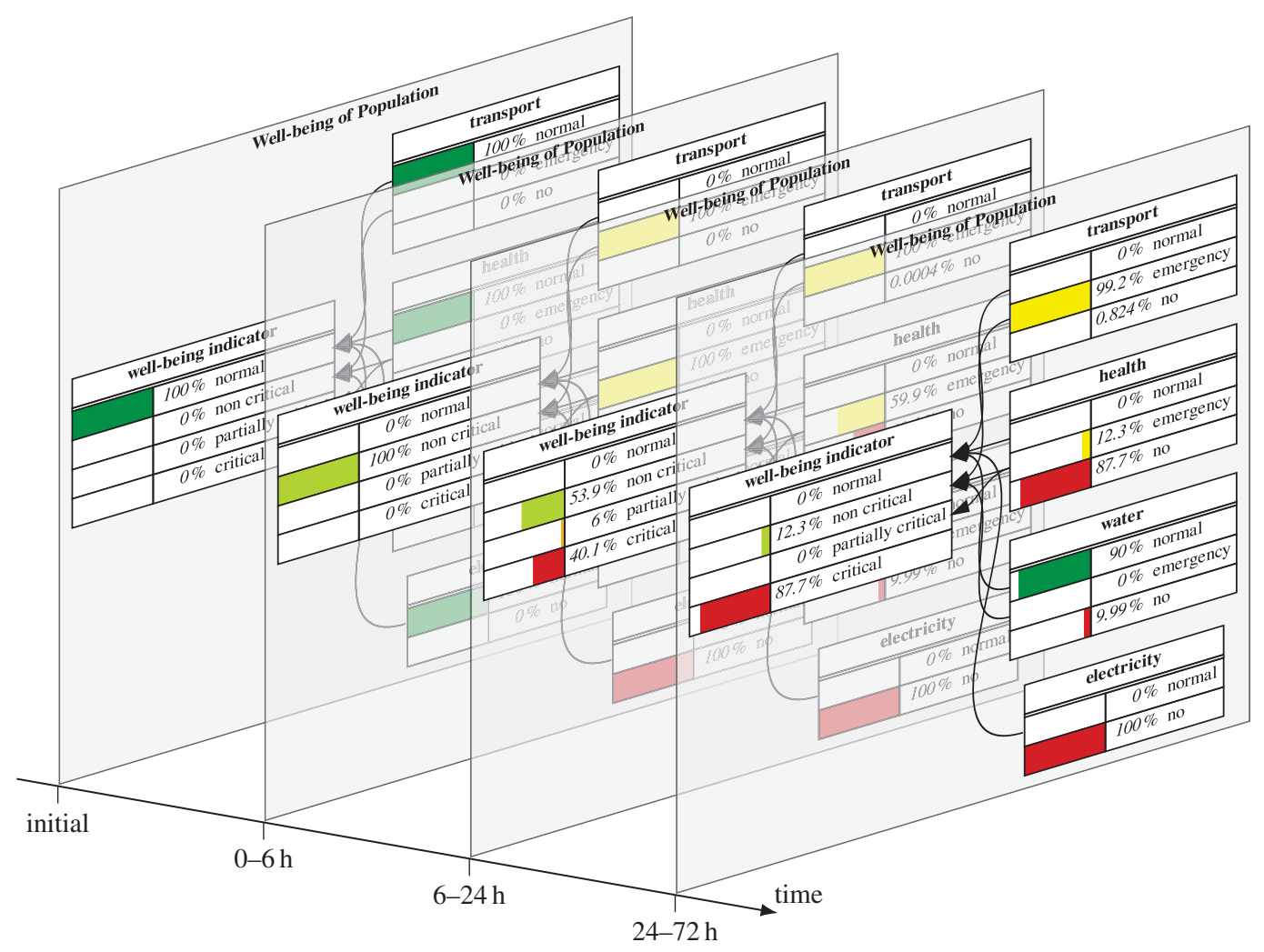

Fig. 5. Development of the impact of the disruptive event on the well-being of the population over time

(2019, December). Return on investment analysis and its applicability to community disaster preparedness activities: Calculating costs and returns. International Journal of Disaster Risk Reduction 41.

Kröger, W. and E. Zio (2011). Vulnerable Systems. London: Springer.

Marti, J. R. (2014). Multisystem simulation: Analysis of critical infrastructures for disaster response. In G. D'Agostino and A. Scala (Eds.), Networks of Networks: The Last Frontier of Complexity, Understanding Complex Systems, pp. 255-277. Cham: Springer International Publishing.

Min, H.-S. J., W. Beyeler, T. Brown, Y. J. Son, and A. T. Jones (2007). Toward modeling and simulation of critical national infrastructure interdependencies. IIE Transactions 39(1), 5771.

Petermann, T., H. Bradke, A. Lüllmann, M. Poetzsch, and U. Riehm (2011). Was bei einem Blackout geschieht. Folgen eines langandauernden und großfächigen Stromausfalls. Studien des Büros für Technikfolgen-Abschätzung beim Deutschen Bundestag ; 33. Berlin: edition sigma.
Rinaldi, S. M., J. P. Peerenboom, and T. K. Kelly (2001). Identifying, understanding, and analyzing critical infrastructure interdependencies. IEEE Control Systems Magazine 21(6), 11-25.

Sanders, P., K. Mehlhorn, M. Dietzfelbinger, and R. Dementiev (2019). Sequential and Prallel Algorithms and Data Structures. The Basic Toolbox. Cham: Springer.

Setola, R., V. Rosato, E. Kyriakides, and E. Rome (Eds.) (2016). Managing the Complexity of Critical Infrastructures. A Modelling and Simulation Approach. Number 90 in Studies in Systems, Decision and Control. Cham: Springer International Publishing, Imprint: SpringerOpen.

Tien, I. (2014). Bayesian Network Methods for Modeling and Reliability Assessment of Infrastructure Systems. Ph. D. thesis.

Tofani, A., G. D'Agostino, and J. Marti (2016). Phenomenological simulators of critical infrastructures. In R. Setola, V. Rosato, E. Kyriakides, and E. Rome (Eds.), Managing the Complexity of Critical Infrastructures. A Modelling and Simulation Approach, Number 90 in Studies in Systems, Decision and Control, pp. 85-107. Cham: Springer International Publishing, Imprint: SpringerOpen. 